ORIGINAL ARTICLE

\title{
Acute effects of different stretching and warm up protocols on some anaerobic motoric tests, flexibility and balance in junior male judokas
}

\author{
Özgür Eken ${ }^{1 \mathrm{ABCDE}}$, Mehmet Z. Özkol ${ }^{2 \mathrm{ABCD}}$, Saadet R. Varol ${ }^{2 \mathrm{ABCD}}$ \\ ${ }^{1}$ Inonu University, Malatya, Turkey \\ ${ }^{2}$ Ege University, Izmir, Turkey
}

Authors' Contribution: A - Study design; B - Data collection; C - Statistical analysis; D - Manuscript Preparation; E - Funds Collection.

\begin{tabular}{|c|c|}
\hline \multicolumn{2}{|l|}{ Abstract } \\
\hline Purpose: & $\begin{array}{l}\text { The aim of this study is to investigate acute effects of different warm-up and stretching protocols, on } 30 \\
\text { m. sprint, flexibility, vertical jump, strength, balance and anaerobic power performances in junior male } \\
\text { judokas. }\end{array}$ \\
\hline Material: & $\begin{array}{l}\text { Twenty sub-elite } 11-14 \text { year old judokas who volunteered to participate in the study (age: } 12,25 \pm 0,96 \\
\text { years; height: } 1,52 \pm 0,11 \mathrm{~cm} \text {; body mass: } 48,06 \pm 14,22 \mathrm{~kg} \text { ). This study consist of four different stretching } \\
\text { and warm up protocols; without stretching (WS); static stretching (SS); dynamic warm up (DW); } \\
\text { dynamic+static warm up (DSW). }\end{array}$ \\
\hline Results: & $\begin{array}{l}\text { The effect of the four stretching and warm up protocols were analysed by an ANOVA for repeated } \\
\text { measures (WS } \times \text { SS } \times \text { DW } \times \text { DSW). After stretching and warm up protocols, } 30 \mathrm{~m} \text {. sprint values are } \\
\text { statistically significance }(p<0.05) \text {. There was find statistically significant between WS and DSW, SS and } \\
\text { DW, DW and DSW }(p<0.05) \text {. There were no significant difference is found on flexibility values between } \\
\text { four stretching and warm up protocols }(p>0.05) \text {. There was only significant difference is found between } \\
\text { WS and SS ( }<0.05 \text { ). Altough leg strength performance wasn't statistically significant ( }>0.05) \text {, there } \\
\text { was found significant differences between WS and DSW, SS and DSW in favour of DSW ( }<<0.05) \text {. Other } \\
\text { parameters like vertical jump, balance and back strength performance weren't statistically significant } \\
\text { after four stretching and warm up protocols. }\end{array}$ \\
\hline Conclusions: & $\begin{array}{l}\text { Consequently it is suggested for coaches and judokas that SS are required for developing flexibility } \\
\text { performance and DSW can suggest for leg strength improvement. }\end{array}$ \\
\hline Keywords: & \\
\hline
\end{tabular}

\section{Introduction}

Judo is a dynamic, physically demanding sport that requires complex skills and tactical excellence for success [1]. As judo athletes have to perform a great number of actions during each match, the physical demand of a single match is high. Typically, judo medalists perform five to seven matches during international competitions, with each match having a 4-minute time limit. If a judo athlete obtains an ippon (fullpoint), the match ends [2]. Although there is no clear scientific evidence, the use of stretching and warm up to improve performance is a common belief among coaches and athletes. Stretching is an integral part of the warm-up process and is placed between the general and specific warm-up prior to participation in training or competition [3]. Static stretching is commonly used because it has been reported to reduce muscle tension that causes increased range of motion and reduce the risk of injury on muscle tendon unite (MTU) [4]. Kay and Blazevich [5] reported that $60 \mathrm{~s}$ or more stretching are more likely to degrade performance and short-term stretching (30-45 s or less) have no detrimental effects. According to some researches, warm up protocol before training or competition has become one of the most important topics for coaches and practitioners and recent studies has shown some positive effects on performance (c) Özgür Eken, Mehmet Z. Özkol, Saadet R. Varol, 2020

doi:10.15561/26649837.2020.0403
$[6,7]$. For decades, practitioners have prescribed warm ups to improve range of motion, decrease muscle soreness and enhance the performance of their athletes [7-10]. In addition, muscle temperature improves the efficiency of muscle glycolysis and high energy phosphate degradation during exercise, which may be from increasing the dependence on anaerobic metabolism and also markedly influence subsequent exercise performance via increases in adenosine triphosphate turnover, muscle cross bridge cycling rate and oxygen uptake kinetics, which enhance muscular function [11]. Besides, improved muscle temperature increases the transmission speed of nevre impulses and increases central-nervous-system function. Enhanced nervous-system function may be particularly critical for activities that require rapid reactions and complex body movements [12].

When we examine the literature, there are lots of studies about stretching and warm up protocols. In these studies different sports branches and different groups of subjects were examined [13-15]. But there is only one study about warm up which include judokas performance [16]. In this study Lum [16] investigated the effect of various warm up protocol on judo specific fitness test performance. He found that during series one, number of throws performed in the upper and lower body PAP (ULB) and lower body (LB) were significantly greater 
than usual competition $(\mathrm{CON})(\mathrm{p}<0.05)$. Only ULB resulted in significantly greater number of total throws $(p<0.01)$ and higher peak power $(p<0.01)$ than CON. Both LB and ULB were significantly lower than CON ( $p$ $<0.01)$. Peak power was moderately correlated to total number of throws performed $(\mathrm{r}=0.4, \mathrm{p}<0.05)$. He suggest that performing ULB before SJFT can result in improved performance and peak power.

The importance of this study was to determine the effects of different stretching and warm up protocols on $30 \mathrm{~m}$. sprint, flexibility, vertical jump, strength, balance and anaerobic power of male judokas aged 11-14 years. Other importance of this study included different warm up protocols like combine warm up (DSW). For this purpose, research hypotheses; (1) flexibility, $30 \mathrm{~m}$. sprint, strength, balance and vertical jump would be affected by different stretching and warm up protocols, and (2) flexibility, $30 \mathrm{~m}$. sprint and strength performance are expected to improve with DSW.

\section{Material and Methods}

\section{Participants}

Twenty healthy male active judokas who exercise three or five times in a week voluntarily attended to this research (age, 11-14 years; height, 152, $\pm 11 \mathrm{~cm}$; body mass, 48,06 $\pm 14,22 \mathrm{~kg}$ ). Judokas trained for more than two years. To be included in the study, the judokas should have had the following characteristics: (a) had at least 2 years of experience in the judo; (b) not have any functional limitation that could interfere in the tests performance; (c) not presented any medical condition that could influence the tests; (d) maintained their regular physical activity during the course of the study. Prior to participation, all subjects were briefed on the requirements and risks involved with the study. Parental consent was sought for subjects. The study started after the approval of the Research Ethics Committee of the institution (14-12.1/7).

Procedure

This study is available just one group in which was included 20 male judokas and there isn't any control group.
Four different streching and warm up protocol which have been applied with content for 48 hours. Twenty judokas into four equal stretching and warm up protocols were randomly taken to exclude the learning effect and the cumulative effect. Each stretching and warm up protocol lasted between about 10-12 minutes. Judokas did the exercises, and two judo coaches supervised each stretching and warm up period. Throughout the familiarization session's judokas were familiarized with stretching and warm up protocols (WS, SS, DW, and DSW). The entire stretching and warm up protocols carried at the same time of day (10.00 am, to avoid the effect of diurnal variations). Each stretching and warm up protocols started with a low tempo (jogging) aerobics run for 5 minutes. Vertical jump, $30 \mathrm{~m}$. sprint, sit and reach flexibility, vertical jump, strength, balance and anaerobic power were measured respectively after each stretching and warm up protocols. This study continued aproximately 10 days. All protocols continued consecutive days. Sit and reach flexibility test was administered using a specially constructed box that had a slide ruler attached to the top. After one practice trial, the best score of three trials was recorded [17]. The anaerobic power of the judokas (peak and mean) was calculated using the Johnson \& Bahamonde Formula [18] which allows calculation of the jump distance, body weight and height length data. Assessment of leg and back strength made by foot-plate of the dynamometer [19]. Flamingo balance test that involved balancing one foot on a certain beam and the purpose is to keep the judokas on foot for a maximum of a period of time on the axis of the foot (single foot) preferred by the test. Support could be obtained from the researcher to get the correct position, after the subject re-gained their balance, the stop watch was activated. The seconds the subject was in balance in a minute was measured. The shortest performance was separated from the other two performances, and the best one was taken and recorded as the Test Point. If the judokas made more than 15 mistakes within 30 seconds after they regained the balance, they are given (0) point [20].

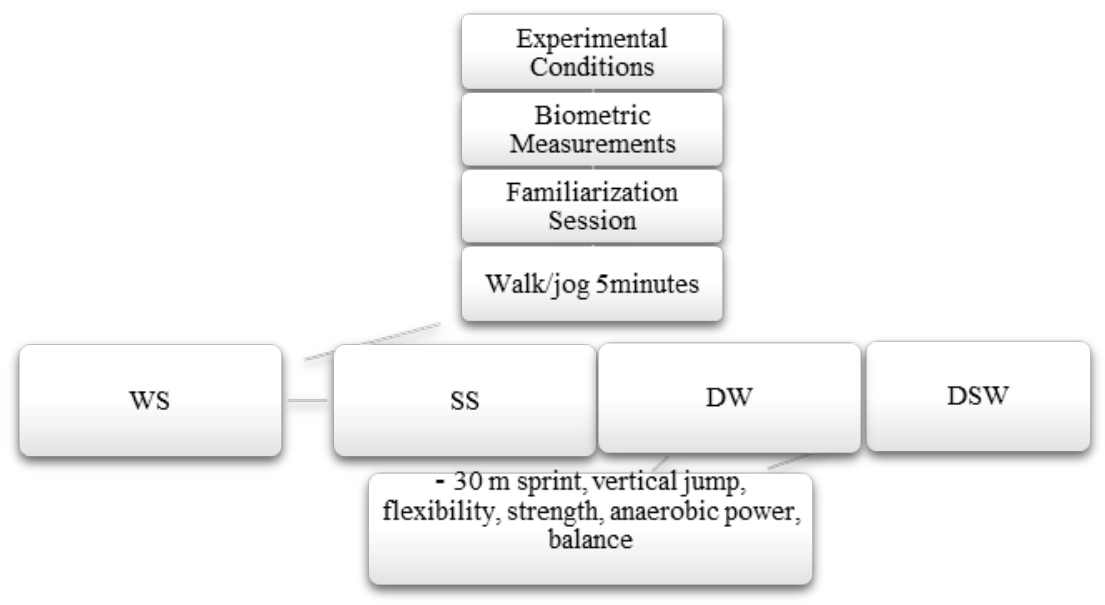

(WS - without stretching; SS - static stretching; DW - dynamic warm up; DSW - dynamic+static warm up)

Figure 1. Experimental design 
No stretching (NS): No stretching protocol consists of 5-minute low-tempo aerobic run. After 5 minutes of lowtempo aerobic run, vertical jump, $30 \mathrm{~m}$. speed, flexibility, strength, balance and anaerobic power performances were measured. The maximum heart rate of the judokas was determined [21]. Then, each subjects' warm up rate was calculated as $30-40 \%$ according to heart rate [22]. Subjects participating in the study were run under the control of the experts. In this way, both the intensity of warm up and the warm up differences between judokas who participate in the study were removed.

Static stretching (SS): After the 5 minutes low tempo run each judokas stretched the target muscle of the right upper and lower extremities slowly and carefully until reaching a position that felt mild discomfort for $15 \times 2$ seconds both sides (adductor stretch, hip rotator stretch, hamstring stretch, quadriceps stretch, calf stretch). The next target to lower extremities muscle was stretched after a rest period of 10 seconds $[8,23]$.

Dynamic warm up $(D W)$ : This warm up protocol consisted of $12 \mathrm{DW}$ exercises that improved from moderate to high intensity (high knee pull, straight-leg march, power skip, light skip, high glute pull, light high knees, light butt kicks, a skip, b skip, rapid high knees, carioca, walking lung). Judokas performed each DW exercise for a distance 15 -meter, rested nearly 10 seconds, and then repeated the similar exercise for 15 -meter as they came back to beginning place. All judokas were continually instructed to maintain proper form (e.g. vertical torso, knees towards chest, up on toes etc.) throughout the performance of the DW [23, 24].

Statistical Analysis

Arithmetic mean and standard deviation were used in the numerical presentation of the data. Conformity of the data to the normal distribution assumption was made by the Shapiro-Wilks test. Repeated Measures of ANOVA were used for repeated different measurements of the normal distribution data, and Bonferroni was used for post-hoc tests to find out which difference occurred. The Friedman test was used for repeated 4 different measurements of normally undistorted data. The Wilcoxon test was performed with binary pairings to find out which measure was derived from the difference. The data were analyzed using the SPSS 18.0 statistical program (SPSS Inc, Chicago, IL) and the statistical significance was accepted as $\mathrm{p}<0.05$.

\section{Results}

Table 1 shows that different stretching and warm up protocols have statistically significant effect on $30 \mathrm{~m}$ sprint performance $(p<0.05)$. According to the Bonferroni analysis results, a statistically significant difference was found between WS and DSW, SS and DW, SS and DSW $(\mathrm{p}<0.05)$.

Table 2 shows that different stretching and warm up protocols have no statistically significant effect on flexibility values ( $p>0.005)$. According to the Bonferroni analysis results, a statistically significant difference was found between WS and SS $(\mathrm{p}<0.05)$.

Table 3 shows that different stretching and warm up protocols have no statistically significant effect on leg strength ( $\mathrm{p}>0.005)$. According to warm up protocols, in favour of DSW, there was significant differences between WS and DSW, SS and DSW $(\mathrm{P}<0.005)$.

Table 4 shows that different stretching and warm up protocols have no statistically significant effect on

Table 1. $30 \mathrm{~m}$. sprint values and differences after different stretching and warm up protocols

\begin{tabular}{|c|c|c|c|c|c|c|c|c|}
\hline Test & WS & SS & DW & DSW & $p$ & Group & $\Delta \%$ & $\mathbf{p}$ \\
\hline 30m. Sprint & $5.72 \pm 0.70$ & $5.90 \pm 0.65$ & $5.64 \pm 0.63$ & $5.45 \pm 0.66$ & 0.00 & $1-2$ & 3.14 & 0.10 \\
\hline \multirow[t]{5}{*}{ (seconds) } & & & & & & $1-3$ & 1.39 & 0.27 \\
\hline & & & & & & $1-4$ & 4.72 & 0.04 \\
\hline & & & & & & $2-3$ & 4.40 & 0.00 \\
\hline & & & & & & $2-4$ & 7.63 & 0.00 \\
\hline & & & & & & $3-4$ & 3.36 & 0.05 \\
\hline
\end{tabular}

( $\Delta \%$ : The rate of change)

Table 2. Flexibility values and differences after different stretching and warm up protocols

\begin{tabular}{|c|c|c|c|c|c|c|c|c|}
\hline Test & WS & SS & DW & DSW & $\mathbf{p}$ & Group & $\Delta \%$ & $\mathbf{p}$ \\
\hline \multirow[t]{6}{*}{ Flexibility $(\mathrm{cm})$} & \multirow[t]{6}{*}{$9.03 \pm 3.23$} & \multirow[t]{6}{*}{$9.93 \pm 3.47$} & \multirow[t]{6}{*}{$9.45 \pm 4.67$} & \multirow[t]{6}{*}{$9.93 \pm 3.99$} & \multirow[t]{6}{*}{0.14} & $1-2$ & 9.96 & 0.04 \\
\hline & & & & & & $1-3$ & 4.65 & 0.23 \\
\hline & & & & & & $1-4$ & 9.96 & 0.08 \\
\hline & & & & & & $2-3$ & 4.83 & 0.54 \\
\hline & & & & & & $2-4$ & - & 1.00 \\
\hline & & & & & & $3-4$ & 5.07 & 0.53 \\
\hline
\end{tabular}

( $\Delta \%$ : The rate of change) 
Table 3. Leg strength values and differences after different stretching and warm up protocols

\begin{tabular}{|c|c|c|c|c|c|c|c|c|}
\hline Test & & SS & DW & DSW & $\mathbf{p}$ & Group & $\Delta \%$ & $\mathbf{p}$ \\
\hline \multirow{6}{*}{$\begin{array}{l}\text { Leg strength } \\
(\mathrm{kg})\end{array}$} & \multirow[t]{6}{*}{$40.05 \pm 16.18$} & \multirow[t]{6}{*}{$40.65 \pm 15.40$} & \multirow[t]{6}{*}{$46.18 \pm 20.01$} & \multirow[t]{6}{*}{$53.85 \pm 24.89$} & \multirow[t]{6}{*}{0.126} & $1-2$ & 1.48 & 0.83 \\
\hline & & & & & & $1-3$ & 15.3 & 0.09 \\
\hline & & & & & & $1-4$ & 34.4 & 0.00 \\
\hline & & & & & & $2-3$ & 13.6 & 0.15 \\
\hline & & & & & & $2-4$ & 32.4 & 0.02 \\
\hline & & & & & & $3-4$ & 16.6 & 0.07 \\
\hline
\end{tabular}

( $\Delta \%$ : The rate of change)

Table 4. Vertical jump, anaerobic power, mean power, balance and back strength

\begin{tabular}{|c|c|c|c|c|c|c|c|c|c|c|c|}
\hline Test & $\begin{array}{l}\text { Stretching } \\
\text { and } \\
\text { Warm up } \\
\text { Protocols }\end{array}$ & $\begin{array}{l}\text { Vertical } \\
\text { Jump } \\
\text { (cm) }\end{array}$ & $\mathbf{p}$ & $\begin{array}{l}\text { Anaerobic } \\
\text { Power } \\
\text { (W) }\end{array}$ & $p$ & $\begin{array}{l}\text { Mean } \\
\text { Power } \\
\text { (W) }\end{array}$ & $\mathbf{p}$ & $\begin{array}{l}\text { Stability } \\
\text { (Number } \\
\text { of Errors) }\end{array}$ & $\mathbf{p}$ & $\begin{array}{l}\text { Back } \\
\text { Strength } \\
\text { (kg) }\end{array}$ & $\mathbf{p}$ \\
\hline $\begin{array}{l}\text { Vertical } \\
\text { jump, } \\
\text { anaerobic }\end{array}$ & NS (1) & $27.65 \pm 6.64$ & \multirow{4}{*}{0.66} & $2747 \pm 795$ & \multirow{4}{*}{0.66} & $954 \pm 357$ & \multirow{4}{*}{0.66} & $5.15 \pm 5.00$ & \multirow{4}{*}{0.58} & $46.75 \pm 19.4$ & \multirow{4}{*}{0.34} \\
\hline power, & SS (2) & $28.00 \pm 7.16$ & & $2774 \pm 866$ & & $968 \pm 396$ & & $4.15 \pm 3.66$ & & $46.14 \pm 21.2$ & \\
\hline mean & DW (3) & $28.40 \pm 7.92$ & & $2805 \pm 873$ & & $985 \pm 400$ & & $4.45 \pm 3.70$ & & $48.75 \pm 18.3$ & \\
\hline $\begin{array}{l}\text { power, } \\
\text { balance, } \\
\text { back } \\
\text { strength }\end{array}$ & DSW (4) & $28.40 \pm 8.15$ & & $2805 \pm 871$ & & $985 \pm 400$ & & $5.00 \pm 3.67$ & & $51.62 \pm 18.1$ & \\
\hline
\end{tabular}

vertical jump, anaerobic power, mean power, stability, back strength $(\mathrm{p}>0.005)$.

\section{Discussion}

The purpose of this study was to determine the effect of different warm up protocol on 30 meter sprint, flexibility, vertical jump, strength, balance and anaerobic power performance on junior male judokas. The other aim is about study to find out which stretching and warm up protocol is more efficient for junior male judokas. The main findings were that no significant differences on vertical jump, anaerobic power, mean power, stability, flexibility, leg strength and back strength $(p>0.05)$. Different stretching and warm up protocols have statistically significant effect on $30 \mathrm{~m}$ sprint performance $(\mathrm{p}<0.05)$. According to the Bonferroni analysis results, a statistically significant difference was found between WS and DSW, SS and DW, SS and DSW $(\mathrm{p}<0.05)$. When the flexibility values were evaluated, a statistically significant difference was found between WS and SS in favor of SS $(\mathrm{p}<0.05)$. There was also significant differences between WS and DSW, SS and DSW on leg strength in favour of DSW $(\mathrm{p}<0.05)$.

Studies in the literature have shown that static stretching exercises reduce sprint performance [13, 25]. Fletcher and Jones, [13] researched the effect of different stretching protocols on 20-m sprint performance in trained rugby union players. They found that the passive static stretch (PSS) and active static stretch (ASST) groups had a significant increase in sprint time $(\mathrm{p}<0.05)$, while the active dynamic stretch (ADS) group had a significant decrease in sprint time $(\mathrm{p}<0.05)$. The decrease in sprint time, observed in the static dynamic stretch (SDS) group, was found to be nonsignificant $(\mathrm{p}<0.05)$. The decrease in performance for the 2 static stretch groups was attributed to an increase in the musculotendinous unit (MTU) compliance, leading to a decrease in the MTU ability to store elastic energy in its eccentric phase. Paradisis et al., [25] aimed to compare the acute effects of static and dynamic stretching on explosive power, flexibility and sprinting ability on adolescent boys and girls and to compare any differences due to gender. They found that static stretching hindered 20 sprint run (SR) and counter movement jump height (CMJ) by $2.5 \%$ and $6.3 \%$ respectively, whereas improved SR by $12.1 \%$. Dynamic stretching hindered $20 \mathrm{SR}$ and CMJ by $0.8 \%$ and $2.2 \%$ respectively, whereas improved SR by $6.5 \%$. Dynamic stretching produces less reduction in 20SR and CMJ than static stretching; however the effect on SR was reverse. Whereas on for the decline in speed performance after static exercises.

Kubo et al. [26] suggested that static stretching can activate viscosity of tendon structures and increase elasticity, there by providing a background for reducing passive resistance and improving joint range of motion after stretching and warm up. In this sense, the low speed performance caused by static stretching in this study may be attributed to neuromuscular causes. On the contrary, dynamic warm up increases the speed performance [27,15]. Alikhajeh et al., [27] researched the purpose of this study was to determine the effects of static stretching, dynamic stretching, and no stretching warm-up trials on 
10-m acceleration, $20 \mathrm{~m}$ maximal speed, and agility of elite male soccer players. They found that there were no significant differences among the different warmup protocols for $10-\mathrm{m}$ acceleration tests. There were significant differences among the different stretching warm-up protocols for the 20-m maximal speed and agility test, with dynamic stretching resulting in significantly better performance than static and no stretching.

Kafkas et al., [14] researched the purpose of this study was to determine the acute effect of different static warm up durations on sub-elite female swimmers on $50 \mathrm{~m}$ freestyle and breaststroke swimming performance. They found that there were significant differences between no warm up (NWU) and static warm up-30 (SS-30), static warm up (SS-60) on freestyle and breaststroke swimming performance (freestyle $\mathrm{p}=.000, \mathrm{p}=.014$ and breaststroke $\mathrm{p}=.005, \mathrm{p}=.000$ respectively). When 30 -seconds and 60 -second warm-up protocols were compared with eachother, a statistically significant difference was found in favor of the 30 seconds warm-up protocol in freestyle and breaststroke $50 \mathrm{~m}$ swimming performance $(\mathrm{p}=.001$ and $\mathrm{p}=.003$ respectively).

According to Bishop [28], active dynamic warm up increases nevre conduction, improves speed-force relationship, increases glycogenolysis and glycolysis, increases the use of high energy phosphate, increases agility performance and strength. According to similar results in this study; It is reported that dynamic exercises may be useful for performance improvement before exercises that are required in advanced level such as sprint exercises. No significant difference was found in flexibility performance after 4 different stretching protocol ( $p>0.05)$. Compared with WS, the best improvement in flexibility performance achieved by static stretching and a $9.96 \%$ increase at $\mathrm{p}<0.05(\mathrm{p}=0.042)$. This development is statistically in significant despite improvement in flexibility performance in DWU $4.65 \%$ $(p=0.236)$ and DSWU 9.96\% $(p=0.86)$. Whereas the increase in flexibility performance after SWU; static exercises increase muscle fitness during stretching and reduce muscle stiffness and viscosity [29]. Similar results have been found in the study, which may be attributed to the increase in muscular stiffness and increased muscle compatibility between muscles after static exercises.

\section{Conclusion}

As a result, it was observed that different stretching and warm up protocol had a positive effect on 30 meter speed, flexibility and leg strength performance. It has been observed that DSW can improve $30 \mathrm{~m}$ sprint and leg strength performances and SS can improve flexibility performances. As a result of this study, 11-14 year old male judokas may suggested to perform DSW for sprint and leg strength performance before training or competition. Beside SS may suggested to improve flexibility performance for 11-14 year old male judokas.

\section{Acknowledgements}

This study was written by abridging Özgür Eken's Ege University Institute of Health Sciences master's thesis. We would like to thank junior male judokas who participated in the study.

\section{Conflicts of Interest}

The authors declare no conflict of interest.

\section{References}

1. Degoutte F. Energy demands during a judo match and recovery. British Journal of Sports Medicine. 2003;37(3):245-249. https://doi.org/10.1136/bjsm.37.3.245

2. Franchini E, Del Vecchio FB, Matsushigue KA, Artioli GG. Physiological profiles of elite judo athletes. Sports Medicine. 2011;41(2):147-166. https://doi.org/10.2165/11538580-000000000-00000

3. Avloniti A, Chatzinikolaou A, Fatouros IG, Avloniti C, Protopapa M, Draganidis D, ... Kambas A. The acute effects of static stretching on speed and agility performance depend on stretch duration and conditioning level. Journal of Strength and Conditioning Research. 2016;30(10):2767-2773. https://doi.org/10.1519/JSC.0000000000000568

4. Young W, Behm D. Should static stretching be used during a warm-up for strength and power activities? National Strength and Conditioning Association. 2002;24:33-37. https://doi.org/10.1519/00126548-200212000-00006

5. Kay AD, Blazevich AJ. Effect of acute static stretch on maximal muscle performance: a systematic review. Medicine Science in Sports and Exercise. 2012;44(1):154-164. https://doi.org/10.1249/MSS.0b013e318225cb27

6. Fradkin AJ, Zazryn TR, Smoliga JM. Effects of warming-up on physical performance: a systematic review with meta-analysis. Journal of Strength and Conditioning Research. 2010;24(1):140-148.
https://doi.org/10.1519/JSC.0b013e3181c643a0

7. Neiva HP, Marques MC, Barbosa TM, Izquierdo M, Marinho DA. Warm-up and performance in competitive swimming. Sports Medicine. 2014;44(3):319-330. https://doi.org/10.1007/s40279-013-0117-y

8. Alter MJ. Sports stretch. Human Kinetics; 2004.

9. Bishop D. Warm up I: potential mechanisms and the effects of passive warm up on exercise performance. Sports Medicine. 2003;33(6):439-454. https://doi.org/10.2165/00007256-200333060-00005

10.Kafkas A, Eken Ö, Kurt C, Kafkas ME. The effects of different stretching and warm-up exercise protocols on 50-meter swimming performance in sub-elite women swimmers. Isokinetics and Exercise Science. 2019;1-9. https://doi.org/10.3233/IES-193141

11.Febbraio MA, Carey MF, Snow RJ, Stathis CG, Hargreaves M. Influence of elevated muscle temperature on metabolism during intense exercise. American Journal of Physiology-Regulatory, Integrative and Comparative Physiology. 1996;271:1251-1255. https://doi.org/10.1152/ajpregu.1996.271.5.R1251

12.Ross A, Leveritt M. Long-term metabolic and skeletal muscle adaptations to short- sprint training: Implications for sprint training and tapering. Sports Medicine. 2001;31(15):1063-1082. https://doi.org/10.2165/00007256-200131150-00003 
13.Fletcher IM, Jones B. The effect of different warmup stretch protocols on 20 meter sprint performance in trained rugby union players. Journal of Strength and Conditioning Research. 2004;18(4):885-888. https://doi.org/10.1519/14493.1

14.Kafkas A, Eken Ö, Çınarlı S, Kafkas ME. Acute effect of static warm-up duration on 50 meter freestyle and breaststroke performance. Journal of Athletic Performance and Nutrition. 2016;3(2):1-10.

15.Ceylan Hİ, Saygın Ö, Yildiz M. Acute effects of different warm-up procedures on $30 \mathrm{~m}$. sprint, slalom dribbling , vertical jump and flexibility performance in women futsal players. Beden Egitimi ve Spor Bilimleri Dergisi. 2014;8(1):19-21.

16.Lum D. Effects of various warm-up protocol on special judo fitness test performance. The Journal of Strength and Conditioning Research. 2019;33(2):459-465. ://doi.org/10.1519/JSC.0000000000001862

17.Lemmink KAPM, Kemper HCG, De Greef MHG, Rispens P, Stevens M. The validity of the circumduction test in elderly men and women. Journal of Aging and Physical Activity. 2003;11(4):433-444. https://doi.org/10.1080/02701367.2003.10609099

18.Johnson DL, Bahamonde R. Power output estimate in university athletes. Journal of Strength and Conditioning Research. 1996;10(3):161-166. https://doi.org/10.1519/00124278-199608000-00006

19.Coldwells A, Atkinson G, Reilly T. Sources of variation in back and leg dynamometry. Ergonomics. 94;37(1):79-86. https://doi.org/10.1080/00140139408963625

20.Altınkök M. Examining the effects of "activity education with coordination" on the development of balance and arm power in 6-year-old primary school children. International Online Journal of Educational Sciences. 2015;7(4):140-147. https://doi.org/10.15345/iojes.2015.04.019

21.Tanaka H, Monahan KD, Seals DR. Age-predicted maximal heart rate revisited. Journal of the American College of Cardiology. 2001;37:153-156. https://doi.org/10.1016/S0735-1097(00)01054-8
22.Karvonen MJ, Kentala E, Mustala O. The effects of training on heart rate: a longitudinal study. Annales Medicinae Experimentalis et Biologiae Fenniae. 1957;35:307-315.

23.Faigenbaum $\mathrm{AD}$, Bellucci $\mathrm{M}$, Bernieri A, Bakker B, Hoorens K. Acute effects of different warm-up protocols on fitness performance in children. Journal of Strength and Conditioning Research. 2005;19(2):376-381. https://doi.org/10.1519/R-15344.1

24.Mann DP, Jones MT. Guidelines to the implementation of a dynamic stretching program. Strength and Conditioning Journal. 1999;21(6):53-55. https://doi.org/10.1519/1533-4295

25.Paradisis GP, Pappas PT, Theodorou AS, Zacharogiannis EG, Skordilis EK, Smirniotou AS. Effects of static and dynamic stretching on sprint and jump performance in boys and girls. The Journal of Strength and Conditioning Research. 2014;28(1):154-160. https://doi.org/10.1519/JSC.0b013e318295d2fb

26.Kubo K, Kanehisa H, Kawakami Y, Fukunaga $\mathrm{T}$. Influence of static stretching on viscoelastic properties of human tendon structures in vivo, Journal of Applied Physiology. 2001;90(2):520-527. https://doi.org/10.1152/jappl.2001.90.2.520

27.Alikhajeh Y, Rahimi NM, Fazeli H, Rahimi RM. Differential stretching protocols during warm up on select performance measures for elite male soccer players. Procedia Social and Behavioral Sciences. 2012;46:1639-1643. https://doi.org/10.1016/j.sbspro.2012.05.353

28.Bishop DJ. Warm up II - Performance changes following active warm up and how to structure the warm up. Sports Medicine. 2003;33(7):483-498. https://doi.org/10.2165/00007256-200333070-00002

29.Behm DG, Chaouachi A. A review of the acute effects of static and dynamic stretching on performance. European Journal of Applied Physiology. 2011;111(11):2633-2651. https://doi.org/10.1007/s00421-011-1879-2

Information about the authors:

Özgür Eken; (Corresponding Author); https://orcid.org/0000-0002-5488-3158; ozgur.eken@inonu.edu.tr; Department of Movement and Training Science, Inonu University, Malatya, Turkey.

Mehmet Z. Özkol; https://orcid.org/0000-0003-2418-7036; zeki.ozkol@gmail.com; Department of Movement and Training Science, Ege University, Izmir, Turkey.

Saadet R. Varol; https://orcid.org/0000-0002-9196-984X; ranavarol@gmail.com; Department of Movement and Training Science, Ege University, Izmir, Turkey.

Cite this article as:

Özgür Eken, Mehmet Z. Özkol, Saadet R. Varol. Acute effects of different stretching and warm up protocols on some anaerobic motoric tests, flexibility and balance in junior male judokas. Pedagogy of physical culture and sports, 2020;24(4):169-174.

https://doi.org/10.15561/26649837.2020.0403

This is an Open Access article distributed under the terms of the Creative Commons Attribution License, which permits unrestricted use, distribution, and reproduction in any medium, provided the original work is properly cited (http://creativecommons.org/licenses/by/4.0/deed.en).

Received: 17.12.2019

Accepted: 12.01.2020; Published: 30.08.2020 